\title{
Rapid Anthropocene realignment of allometric scaling rules 00
}

\author{
Luca Santini $^{1,2}$ (이 | Nick J. B. Isaac ${ }^{3} \odot$
}

${ }^{1}$ Department of Biology and Biotechnologies "Charles Darwin", Sapienza Università di Roma, Rome, Italy ${ }^{2}$ National Research Council, Institute of Research on Terrestrial Ecosystems (CNRIRET), Monterotondo (Rome), Italy

${ }^{3}$ UK Centre for Ecology \& Hydrology, Wallingford, UK

\section{Correspondence}

Luca Santini, Department of Biology and Biotechnologies, Sapienza Università di Roma, Rome, Italy.

Email: luca.santini.eco@gmail.com

Editor: Ana Rodrigues

\begin{abstract}
The negative relationship between body size and population density in mammals is often interpreted as resulting from energetic constraints. In a global change scenario, however, this relationship might be expected to change, given the sizedependent nature of anthropogenic pressures and vulnerability to extinction. Here we test whether the size-density relationship (SDR) in mammals has changed over the last 50 years. We show that the relationship has shifted down and became shallower, corresponding to a decline in population density of $31-73 \%$, for the largest and smallest mammals, respectively. However, the SDRs became steeper in some groups (e.g. carnivores) and shallower in others (e.g. herbivores). The Anthropocene reorganisation of biotic systems is apparent in macroecological relationships, reinforcing the notion that biodiversity pattens are contingent upon conditions at the time of investigation. We call for an increased attention to the role of global change on macroecological inferences.
\end{abstract}

\section{K E Y W O R D S}

energy-equivalence rule, global change, mammals, population density, size-density relationship

\section{INTRODUCTION}

Macroecology seeks to establish relationships that are informative of nature's underlying mechanisms. The relationship between species body mass and population density, also known as the size-density relationship (SDR), has long been studied to shed light on how the abundance of animals scales with their size (Allen et al., 2002; Brown et al., 2004; Damuth, 1981; White et al., 2007). Studies have shown that a clear negative relationship exists (Damuth, 1981), which was initially explained in terms of the scaling between body mass and metabolic rate (Kleiber, 1932). Damuth $(1981,1987)$ noted that the scaling coefficients between body mass and metabolic rate $(\sim 0.75)$ and body mass and population density were inverse $(c .-0.75)$, suggesting that the energy flux was invariant to body mass, that is, energyequivalence rule (Brown et al., 2004). The energyequivalence rule implied an energetic tradeoff between physiological and ecological process, resulting in energy in ecosystems being distributed independently of the size of organisms. This theory was later challenged on empirical and theoretical grounds (Carbone et al., 2007; Delong \& Vasseur, 2012; Isaac et al., 2011, 2013; McGill, 2008; Munn et al., 2013; Nilsen et al., 2013). For example, the SDR varies across taxa (Isaac et al., 2011; Pedersen et al., 2017b) and trophic levels (Silva et al., 1997), with higher trophic levels typically showing lower intercepts and steeper slopes. Despite this variation in the SDR, Hatton et al., (2019) have recently shown that the energy-equivalence prediction holds across a wide taxonomic and body mass range. Competing explanations for the existence of the SDR in endotherms have focused on differential resource availability and accessibility across trophic levels, and energy conversion efficiency (Blackburn et al., 1993; Carbone \& Gittleman, 2002; Damuth, 1987; Ernest et al., 2003; Silva et al., 1997). 
An increasing number of studies suggest that what we know about the natural word is contingent on the conditions at the time of investigation (Santini et al., 2017). Large-scale emergent properties are assumed to arise from ecosystems tending to an equilibrium; however, equilibria are unlikely static but shift over time (McGill, 2011), such that ecosystems, communities and species may be at disequilibrium. Example include species distributions that lag behind environmental changes due to limited dispersal capacities (Araújo \& Pearson, 2005; Svenning \& Skov, 2004), and populations that are locally doomed to extinction resulting from habitat loss and fragmentation but persist due to slow demography (i.e. extinction debts; Diamond, 1972; Tilman et al., 1994). On top of this, the Anthropocene is characterised by a rapid reshuffling of biological communities (Dornelas et al., 2014; McGill et al., 2015), potentially disrupting the equilibria under which patterns such as the SDR emerged. Examples are the Bergmann rule that has been altered by the extinction of large-bodied species in temperate areas (Faurby \& Araújo, 2016; Rapacciuolo et al., 2017; Santini et al., 2017), patterns of geographic range and species richness that appear shaped at least as much by human factors as by climate and biogeography ( $\mathrm{Di}$ Marco \& Santini, 2015; Torres-Romero \& Olalla-Tárraga 2015). Similarly, in anthropogenic areas the abundance of some species has increased (Tucker et al., 2020) and movements decreased (Tucker et al., 2018). Activity patterns have been altered globally with nocturnal activity increasing in more disturbed environments (Gaynor et al., 2018). Even the discrimination of biogeographic realms changes depending on whether introduced and extinct species are considered in the clustering algorithm (Bernardo-Madrid et al., 2019). Analogously, authors have claimed that deviations from the energyequivalence rule may result from the historical reassembly of mammal communities (Munn et al., 2013).

There are several reasons to expect that the SDR is unstable over time. Abundance can change in response to direct persecution, harvesting (Benítez-López et al., 2017), habitat degradation and fragmentation (Pfeifer et al., 2017), supplemental resources (Yirga et al., 2013), predation or competition release (Terborgh, 2015), or human shield effects (Berger, 2007). At the same time, these changes are uneven with respect to body mass. Larger species have shown to be intrinsically more at risk of extinction because of diminished resilience, or because they are preferentially affected or targeted by human actions (Cardillo et al., 2005; Purvis et al., 2000). Threatening processes do not act evenly across the range of mammalian body sizes, e.g. small species appear to be more sensitive to habitat loss and degradation, whereas large species to be more sensitive to overharvesting (Gonzalez-Suarez et al., 2013; Ripple et al., 2017). Mammal and bird faunas are projected to become increasingly dominated by small-bodied species (Cooke et al., 2019).
The action of these anthropogenic pressures, simultaneously and/or heterogeneously, creates potential for both the intercept and slope of the SDR to shift over time. By contrast, theory emphasises fixed physiological and environmental constraints as the primary forces responsible for allometric scaling parameters, so the null expectation would be that these constraints somehow overcome or balance out the effects of anthropogenic forcing (Figure 1a). Anthropogenic pressures have the potential to exert directional pressure on both parameters of the SDR: a general reduction in wild biomass would reduce the intercept (Figure 1b), whereas sizedependent declines could lead to a reduction in the slope (Figure 1c), although these are not mutually exclusive (Figure 1d). These changes might be further complicated by extinctions (resulting in the removal of species from the SDR) and trophic interactions (e.g. reduction in predation pressure and competitive release).

Here we assess if and how the SDR has shifted in time across a 50-year period that coincided with unprecedented transformation of natural habitats. We focus on mammals, which have formed the basis of many SDR studies (Damuth, 1981, 1987; Pedersen et al., 2017a), and for which population density data have been collected for a long time and body mass data are largely available (Santini et al., 2018). Because species of different trophic groups exhibit different relationships (Carbone \& Gittleman, 2002; Silva et al., 1997) and can be threatened by, or benefit, from different environmental changes (Berger, 2007; Cooke et al., 2019; Estes et al., 2011; Terborgh, 2015), we also assess if and how these shifts vary across diet categories. Our general hypothesis is that anthropogenic pressures have led to systematic shifts in the parameters of the SDR over the course of a human lifetime, with a general decrease in both intercept and slope parameters. We expect this shift to be particularly evident in carnivores where large species have suffered strong declines (Ripple et al., 2014).

\section{METHODS}

\section{Data}

We extracted all population density estimates for mammals from an updated unpublished version TetraDENSITY database, totalling 16,786 estimates for 839 species (Santini et al., 2018). We only retained data for which the sampling method was reported, and year and location of sampling were known. We excluded all density estimates of non-native species. When density estimates were the results of sampling across several years (e.g. mark-recapture studies in large carnivores; $2-4$ years), we took the middle year as reference sampling time. This dataset resulted in 13,672 population density estimates for 757 species of mammals. The sampling years spanned between 1918 
Intercept
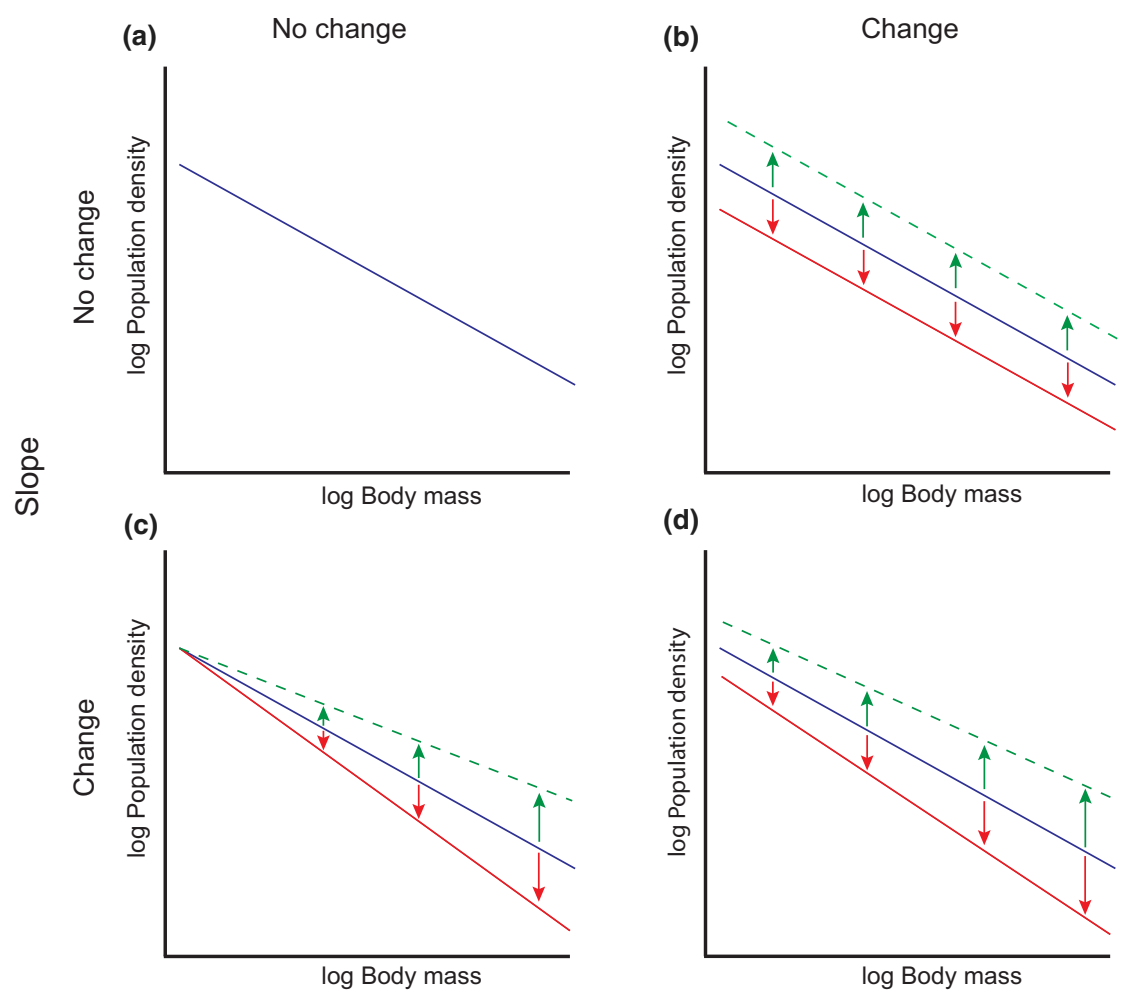

F I G U R E 1 Conceptual representation of the four competing hypotheses on the shift in intercept and slope of the relationship between body mass and population density. (a) Average population densities have remained unchanged and the relationship does not change; (b) Species of different size change in population density at a similar rate, that is, only intercept change; (c) Only large species change in population density, that is, only the slope changes; (d) All species change in population density but at different rates depending on their body mass, that is, both the intercept and the slope change

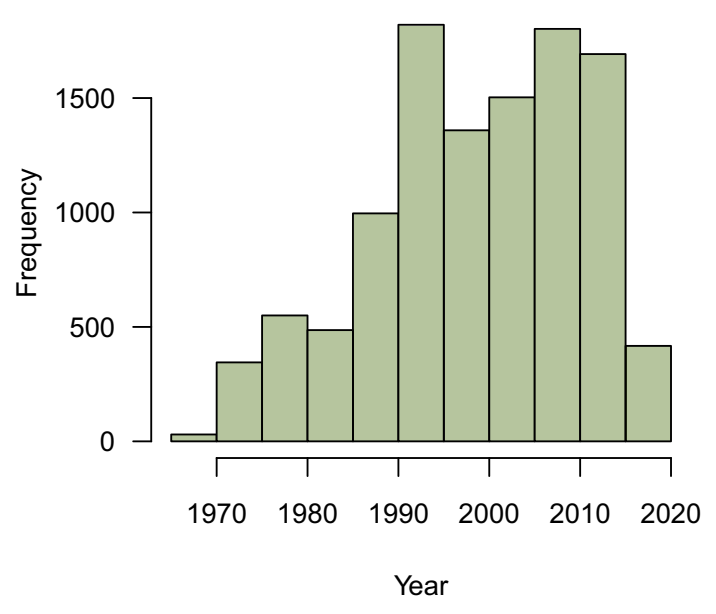

F IG URE 2 Distribution of the sampling years of the population density estimates mammals

and 2019, but were mostly distributed between 1970 and 2019 (Figure 2). In order to avoid possible biases due to limited sampling before 1970, we reduced the dataset to density estimates collected between 1970 and 2020. This reduced the datasets to 13,088 estimates for 744 species in mammals.
Body mass and diet information for all mammals were extracted from EltonTraits database v. 1.0 (Wilman et al., 2014), which collated most of the body mass data from the MOM database (Smith et al., 2003). EltonTraits provides proportions of diet items in mammals, which we used to classified mammals into six of the seven diet categories defined in Silva et al., (1997). Species with $\geq 90 \%$ vertebrate-based diet were classified as carnivores $(n=770$, sps $=34)$ and those $\geq 70 \%$ invertebrate-based diet as insectivores $(n=303$, sps $=64)$. Species with $<20 \%$ of animalbased diet were classified as frugivore if with $\geq 40 \%$ fruit in diet $(n=1574$, sps $=160)$ and as granivores if with $\geq 30 \%$ seed-based diet $(n=789$, sps $=64)$. Because EltonTraits does not differentiate between leaves and grass, we did not distinguish herbivores from folivores as in Silva et al., (1997) and clumped them together into one single herbivore category, defined as species with $\geq 70 \%$ plant-based diet excluding fruits, seeds and nectar, and $<=10 \%$ of meat-based diet $(n=6803$, sps $=235)$. All species that did not fit the previous categories were classified as omnivores $(n=2849$, sps $=192$ ).

The dataset used in this study is archived in Figshare (https://doi.org/10.6084/m9.figshare.14199302). 


\section{Modelling approach}

We fitted a set of generalised mixed effect linear models (GLMM) using a gaussian distribution to test and compare our hypotheses (Table 1). Both population density and body mass were $\log 10$-transformed. All models included a random effect at the level of species to control for the effect of pseudo-replications and possible species turnover through time. We also included a random effect to control for different sampling methodologies broadly classified into eight categories: censuses ('complete' counts, which assume full detection of individuals), distance sampling (including different algorithms and sampling design), home range extrapolation (derived from home range area estimation), mark-recapture (including different algorithms and capture approaches), N-Mixture models, Random Encounter models, incomplete counts (any incomplete count that is extrapolated to a larger area), trapping (removal methods, indicate the minimum number known to be alive).

The model representing our null hypothesis (Figure 1a) only included body mass (Table 1). To assess whether the intercept has changed, we tested the additive effect of time by including sampling year as a fixed effect. To assess whether the slope has changed, we tested the effect of time along the body mass range by including an interaction term between sampling year and body mass (Table 1). In order to test whether our hypotheses were only valid for a specific diet category, we repeated the model selection for each diet category separately.

Models were compared using the Akaike Information Criterion (AIC). We also present results using the Bayesian Information Criterion (BIC), which tends to be more conservative than AIC and is thus considered more suitable for very large sample sizes (Raffalovich et al., 2008). We tested the residuals of the selected model for spatial autocorrelation using Moran I and phylogenetic autocorrelation using Pagel's lambda and 100 random phylogenetic trees from Upham et al., (2019). We also plot the residuals against time to assess a possible temporal autocorrelation effect in the residuals.
Sampling effort across geographic areas may have changed over time (e.g. from natural to anthropogenic areas), potentially influencing our results. We therefore repeated the model selection including the human influence index variables in all models tested (Venter et al., 2016; Appendix S1). Finally, in order to provide an independent line of evidence of our methodological approach, we also fit simple allometric relationships on data collected at different times (1975-1995 and 19962020; Appendix S2).

\section{RESULTS}

The most supported model explaining the SDR across all species was the one accounting for a shift in both intercept and slope (IntSlope model; Table 2, Table S1, Figure 3). The same model was the most supported according to AIC in all diet categories except for insectivores and folivores (Table 2, Table S1, Figure 4). For these groups the most parsimonious models were the Null and the Intercept-only model, respectively (Table 2, Table S1), but in both cases the IntSlope model was competitive (within 2 AIC units from the best model).

Projecting the model for the 1970 and for 2020, the SDR across all diet categories shifted down and became shallower $(\Delta$ Intercept $=-0.35 ; \Delta$ Slope $=-0.10)$. However, the qualitative nature and extent of the change varied across diet categories (Figures 3-5). In frugivores the relationship became shallower $(\Delta$ Slope $=0.72$ ), while in herbivores and omnivores the SDR shifted down ( $\Delta$ Intercept $=-0.17-0.44)$ and became shallower $(\Delta$ Slope $=0.19-0.24)$. In granivores and carnivores the SDR shifted down $(\Delta$ Intercept $=$ -0.74 to -1.56$)$ but became steeper $(\Delta$ Slope $=-0.72$ to -0.80$)$. On the contrary, the most parsimonious model for insectivores did not detect any change. These changes equate to substantial relative changes in the average abundance of species when transformed back to natural scale (Figure 5c). Considering the extreme body masses per dataset, on average small species decreased by $73 \%$ whereas large by $31 \%$, with the greatest

\begin{tabular}{|c|c|c|c|}
\hline Hypothesis & Model & Formula & Explanation \\
\hline Null hypothesis & Null & $\mathrm{PD} \sim \mathrm{BM}$ & $\begin{array}{l}\text { Population densities are constant } \\
\text { over time }\end{array}$ \\
\hline Intercept shifts & IntOnly & $\begin{array}{l}\mathrm{PD} \sim \mathrm{BM}+ \\
\quad \text { Year }\end{array}$ & $\begin{array}{l}\text { Population densities shift over } \\
\text { time }\end{array}$ \\
\hline Slope shifts & SlopeOnly & $\begin{array}{l}\mathrm{PD} \sim \mathrm{BM}+ \\
\quad \text { Year:BM }\end{array}$ & $\begin{array}{l}\text { Size-dependent shift in population } \\
\text { density where the intercept } \\
\text { does not change }\end{array}$ \\
\hline $\begin{array}{r}\text { Intercept and } \\
\text { slope shift }\end{array}$ & IntSlope & $\begin{array}{c}\mathrm{PD} \sim \mathrm{BM}+ \\
\text { Year }+ \\
\text { Year:BM }\end{array}$ & $\begin{array}{l}\text { Population densities shift } \\
\text { over time but change is } \\
\text { size-dependent }\end{array}$ \\
\hline
\end{tabular}

TA B LE 1 Hypotheses tested and corresponding fixed effect model formulas

$\mathrm{PD}=\log 10$ population density; $\mathrm{BM}=\log _{10}$ body mass; Year $=$ sampling year . 
TABLE 2 Comparison of models tested through AIC and BIC

\begin{tabular}{|c|c|c|c|c|c|c|c|c|c|c|}
\hline & Model & $n$ & df & LL & AIC & $\Delta \mathrm{AIC}$ & AIC $\omega$ & BIC & $\Delta \mathrm{BIC}$ & BIC $\omega$ \\
\hline \multirow{2}{*}{ AllDiets } & IntOnly & & 6 & -12609.37 & 25230.74 & 8.82 & 0.01 & 25275.62 & 1.34 & 0.34 \\
\hline & Null & & 5 & -12670.88 & 25351.75 & 129.83 & 0 & 25389.15 & 114.87 & 0 \\
\hline \multirow[t]{3}{*}{ Carnivore } & IntSlope & 770 & 7 & -642.52 & 1299.05 & $\mathbf{0}$ & 0.82 & 1331.58 & 1.42 & 0.3 \\
\hline & SlopeOnly & & 6 & -647.1 & 1306.19 & 7.14 & 0.02 & 1334.07 & 3.92 & 0.09 \\
\hline & Null & & 5 & -674.2 & 1358.41 & 59.35 & 0 & 1381.64 & 51.48 & 0 \\
\hline \multirow[t]{3}{*}{ Frugivores } & IntSlope & 1574 & 7 & -1392.27 & 2798.54 & 0 & 0.61 & 2836.07 & 4.2 & 0.08 \\
\hline & SlopeOnly & & 6 & -1393.85 & 2799.70 & 1.16 & 0.34 & 2831.87 & 0 & 0.68 \\
\hline & IntOnly & & 6 & -1396.07 & 2804.14 & 5.60 & 0.04 & 2836.31 & 4.44 & 0.07 \\
\hline \multirow{2}{*}{ Granivore } & SlopeOnly & & 6 & -625.93 & 1263.86 & 14.56 & 0 & 1291.88 & 9.88 & 0.01 \\
\hline & Null & & 5 & -629.94 & 1269.88 & 20.57 & 0 & 1293.23 & 11.23 & 0 \\
\hline \multirow[t]{4}{*}{ Herbivore } & IntSlope & 6803 & 7 & -6727.83 & 13469.65 & 0 & 1 & 13517.43 & 0 & 0.93 \\
\hline & IntOnly & & 6 & -6734.82 & 13481.65 & 11.99 & 0 & 13522.6 & 5.17 & 0.07 \\
\hline & Null & & 5 & -6753.9 & 13517.81 & 48.15 & 0 & 13551.93 & 34.5 & 0 \\
\hline & SlopeOnly & & 6 & -6752.97 & 13517.94 & 48.28 & 0 & 13558.89 & 41.46 & 0 \\
\hline \multirow[t]{2}{*}{ Insectivore } & IntSlope & 303 & 7 & -356.39 & 726.79 & 0 & 0.44 & 752.78 & 6.609 & 0.03 \\
\hline & Null & & 5 & -358.80 & 727.60 & 0.82 & 0.29 & 746.17 & 0 & 0.85 \\
\hline
\end{tabular}

$n=$ sample size; $\mathrm{df}=$ number of parameters; $\mathrm{LL}=\log$-likelihood; $\Delta=$ delta AIC or BIC; $\omega=$ AIC or BIC weights. The best model according to AIC is highlighted in bold.

percentage changes predicted for carnivores and frugivores (Figure $5 \mathrm{c}$ ).

BIC-based selection concurs for all groups except in frugivores, carnivores and omnivores. In frugivores the null model is more supported by BIC, whereas in carnivores and omnivores the most supported models by AIC are also ranked as competitive by BIC, but the interceptonly model would be preferred as more parsimonious. We did not detect an effect of phylogenetic, spatial or temporal autocorrelation in the residuals of the selected models (Table S2, Fig. S1-S2).

The sampling effort along the human influence index gradient changed over time, but inconsistently across diet categories (Fig. S5). Controlling for this effect in the model selection only changed slightly our results, and did not change the overall conclusions (Table S3 and S4, Fig. S6-S7, Appendix S1). Similarly, fitting two independent size-density regressions on data collected in different periods lead to qualitatively similar results (Table S5, Fig. S8 and S9, Appendix S2).

\section{DISCUSSION}

Our results suggest that the relationship between body mass and population density, which has long been subject of macroecological investigation (Allen et al., 2002; Brown et al., 2004; Damuth, 1981; Isaac et al., 2013; White et al., 2007), has changed within a relatively short time frame. Mammals declined in density on average, but the changes have been non-random with respect to body size and diet category. The changes detected in the allometric relationships for the diet categories is substantial. Omnivores and herbivores, which appear to have changed less than other groups, exhibit a decrease of -0.19 to -0.25 in the slope, which is enough to change substantially the conclusions of any test against the 


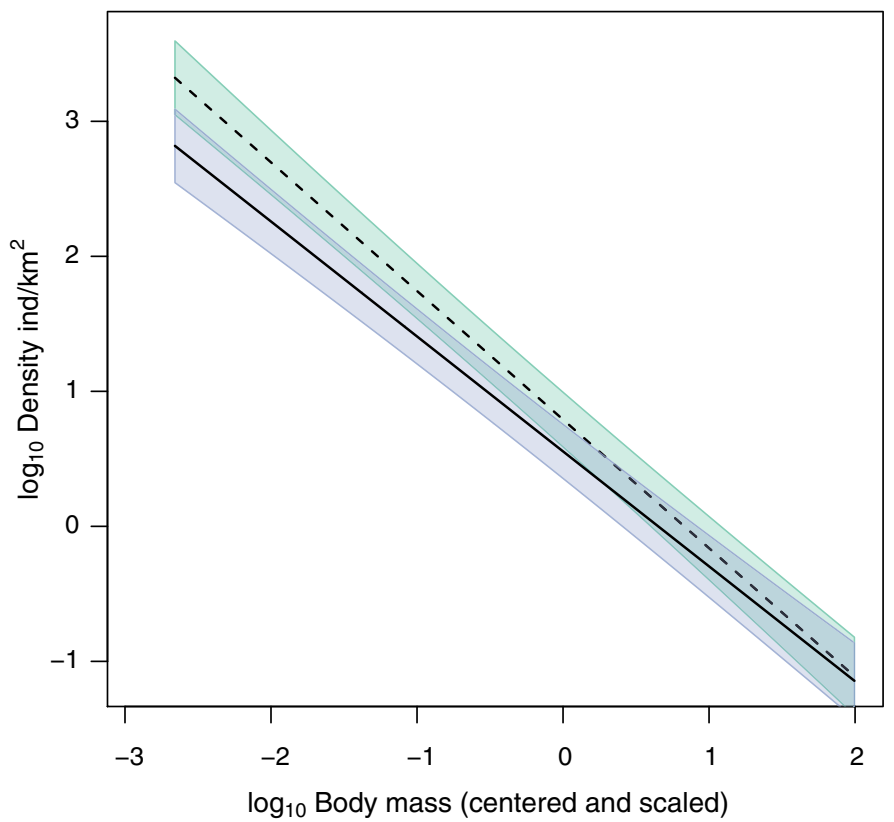

F I G U RE 3 Predicted change in average population density of mammals along the full range of body mass. Dashed line = 1970; Solid line $=2020$. Shaded areas encompass the $95 \%$-prediction interval of the relationships (green $=1970$; violet $=2020)$. Body mass values span the entire range of body masses, but values are centred and scaled

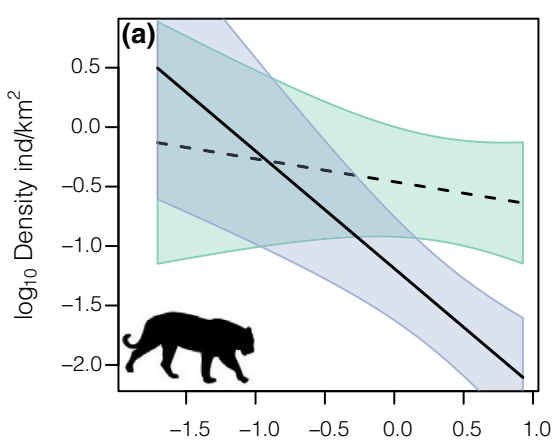

$\log _{10}$ Body mass (centered and scaled)

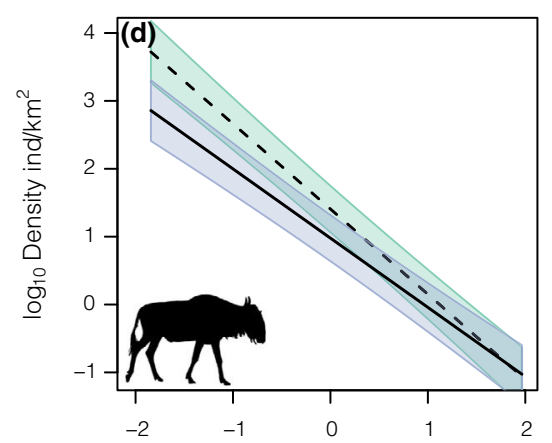

$\log _{10}$ Body mass (centered and scaled)

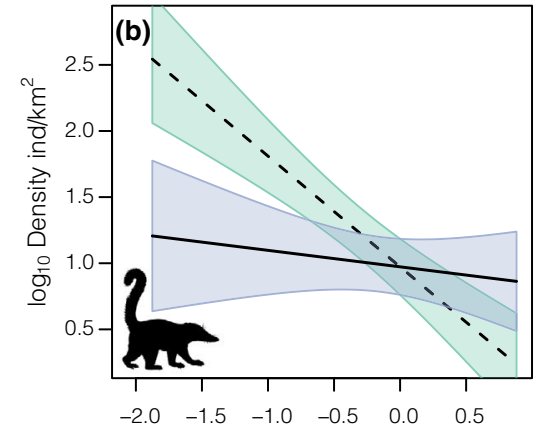

$\log _{10}$ Body mass (centered and scaled)

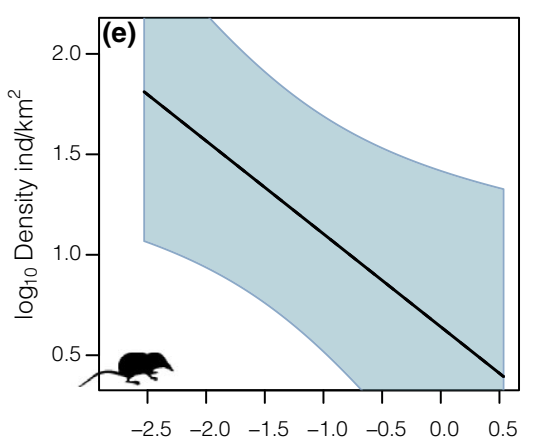

$\log _{10}$ Body mass (centered and scaled)

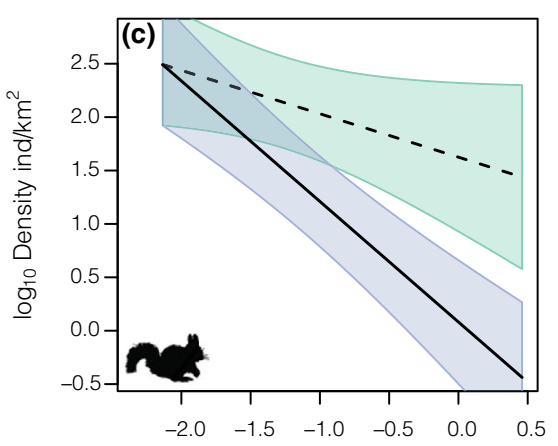

$\log _{10}$ Body mass (centered and scaled)

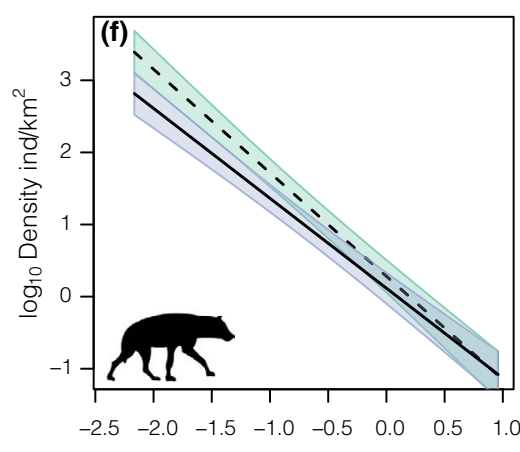

$\log _{10}$ Body mass (centered and scaled)

F IG U R E 4 Predicted change in average population density of mammals along the full range of body mass. Dashed line = 1970; Solid line $=2020$. (a) carnivores, (b) frugivores, (c) granivores, (d) herbivores, (e) insectivores, (f) omnivores. Shaded areas encompass the $95 \%$-prediction interval of the relationships ( green $=1970$; violet $=2020)$. Body mass values span the entire range of body masses per diet category, but values are centred and scaled

Damuth's rule value of -0.75 . Interestingly, the change in the slope of the global relationship was more limited, presumably due to a compensation effect between diet groups, that is, the slope became shallower in some groups but steeper in others. These findings demonstrate that the Anthropocene reorganisation of biotic systems 

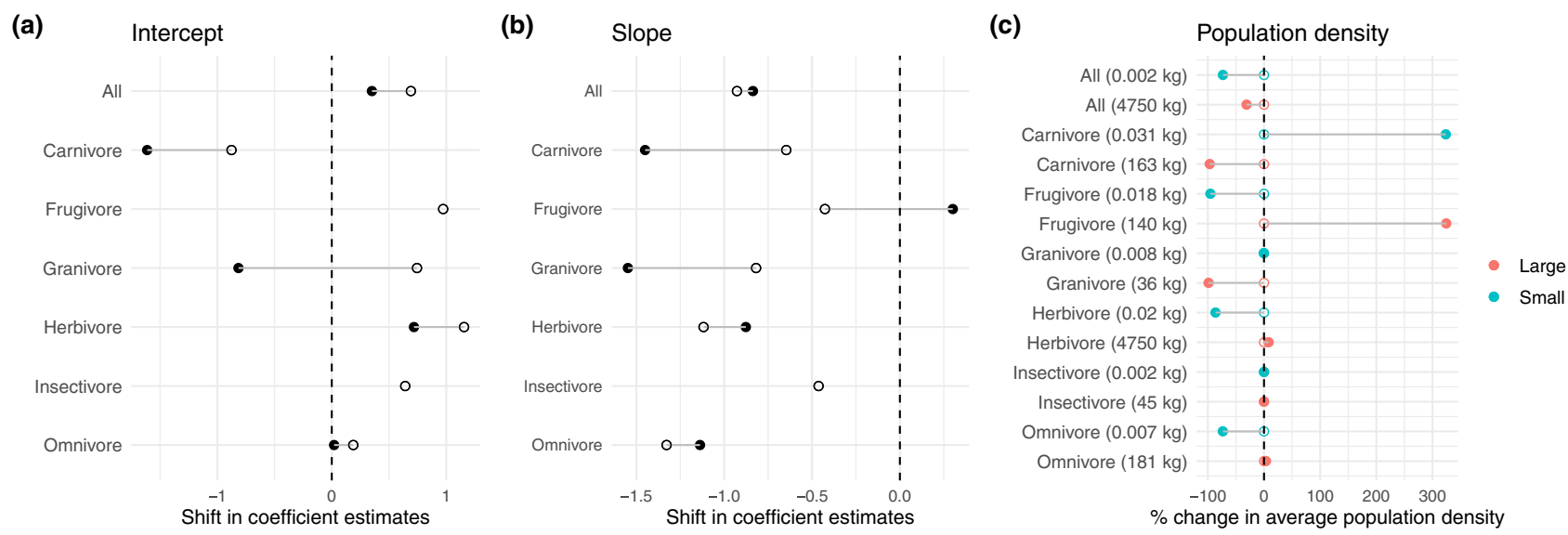

F I G U R E 5 Change in models' intercept (a) and slope (b) coefficients for 1970 (empty points) and 2020 (full points) estimated based on the additive term of the 'Year' variable (change in intercept) and the interaction term between 'Body mass' and 'Year' (change in slope). (c) Shows the predicted changes in average population density from 1970 to 2020 for the smallest and largest species in each diet category

is apparent in macroecological relationships that were previously believed to results from energetic constraints only (Brown et al., 2004; Damuth, 1987), casting doubts on our ability to identify 'natural' patterns reflecting pure ecological mechanisms.

The observation that the SDR has a scaling exponent of approximately the inverse of the Kleiber's metabolic scaling exponent led to the conclusion that energy flux in ecosystems is equally distributed across species of different sizes. Our results suggest that the exact SDR scaling coefficient may be a matter of timing and the extent to which ecosystems have been exposed to anthropogenic forcing. It follows that we cannot be confident that SDR parameters provide evidence for any kind of equilibrium. These findings have several implications for our understanding of macroecology. For example, diet categories exhibit different intercepts that have been interpreted as a matter of resource availability (Silva et al., 1997), yet the extent of these difference changes over time, therefore possibly reflecting additional processes (e.g. human exploitation, habitat degradation, resource depletion or supplementation, or human-wildlife conflicts). The somewhat unexpected result of a larger decrease in small than large herbivores may mirror the larger decrease in large carnivores, indicating an overall predation release effect (Hoeks et al., 2020). Marquet (2002) noted that the steeper SDR relationship in carnivores has long puzzled ecologists. While this has been explained considering that large preys tend to be distributed less evenly therefore resulting less accessible than small ones (Carbone et al., 2007), our results suggest that the observed steeper slope may be the result of the widespread decline of large carnivores (Ripple et al., 2014) — and possibly also influenced by the increase of mesocarnivores (Prugh et al., 2009; Ritchie \& Johnson, 2009) - a process that presumably started long before 1970 . In fact, while the change in 50 years only is striking, it is likely that changes in species average abundance started much earlier than the first macroecological investigations of the body mass - density relationship (Damuth, 1981). We can only speculate that 'pre-Anthropocene' regression lines were probably higher and shallower than observed in available empirical data. In principle, assuming the shift is entirely attributable to human impact and we were able to estimate the decline with actual anthropogenic pressures, it would be possible to estimate the 'natural' regression line (Santini et al., 2017). Yet, this presents several complications in this case, especially considering that every species may respond differently to human pressures. Any attempt to estimate a pre-Anthropocene SDR would be highly sensitive to assumptions about the population densities of extinct megafauna. Besides, species abundances in ecosystems are strictly linked, so species may increase or decrease in abundance because of the relative abundance of other coexisting species (Terborgh, 2015). Other authors have argued that natural baseline could be estimated by focusing on historically less impacted regions of the world (e.g. Africa; Floejgaard et al. 2020), yet several studies have shown these regions to be have also been substantially negatively impacted by humans (Malhi et al., 2016; Newbold et al., 2016). A different and promising avenue of research, would be estimating 'natural' abundances through the use of mechanistic ecosystem models, for example, the Madingley model (Harfoot et al., 2014). Interestingly, validation of the emergent properties of this model exhibited higher densities than observed in reality, which has been attributed to a number of factors, among which the overall decrease in natural population densities due to human impact (Harfoot et al., 2014). Further improvement of global ecosystem models may open up possibilities to estimate natural baselines for macroecology.

Here we have focused on the global SDR (sensu White et al., 2007), which encompasses data collected from different communities worldwide, therefore including populations that do not coexist. This contrasts with the local SDR that focuses on a single community (e.g. Cosset et al., 2020; Russo et al., 2003). Therefore, our 
results do not necessarily challenge local SDR (Cosset et al., 2020), but global SDR, indicating that conclusions are sensitive to the time of investigation. Changes in the global SDR are more difficult to interpret (White et al., 2007) because do not imply changes and compensation at the community level, but rather an overall change that can emerge from the independent changes of many communities. The consistency of results across several diet categories suggests that conclusions are not driven by a small set of species in a few locations. The global SDR is potentially more sensitive to spatial and taxonomic biases in the data, whereas the local SDR is potentially more sensitive to noise due to restricted species sets and smaller ranges of body mass values. Given the challenge of collecting representative sets of community-level data, the theory underlying SDR has been mostly developed by collecting data from the literature and fitting global SDRs (Brown et al., 2004; Damuth, 1987; Hatton et al., 2019; White et al., 2007).

The mismatch between AIC-based and BIC-based selection reflects the highly noisy nature of population density data. While our sample sizes were undoubtedly large, detecting a temporal trend within 50 years in a dataset including many species and their trends require a considerable sample size, so uncertainty remain regarding the change in SDR in frugivores, omnivores and carnivores. The likelihood of their models including an interactive term was higher, but not sufficiently high to undeniably justify increased model complexity.

The relationship between sampling time and human influence index indicates that empirical density estimates suffer of temporal biases which may partly explain our results (Appendix S1). For example, it was noted that global size-density relationships (including species from different ecosystems) may be biased towards higher densities, as researchers often study populations where they are mostly abundant (Marquet et al., 1995). This phenomenon could change in intensity over time, perhaps because researchers may have become better able to estimate low-density populations. Controlling for the effect of human influence index, however, does not substantially alter our results, which consistently show a generalised decline in the intercept and a change in the slopes of the size-density relationship (Appendix S1).

Similarly, species sampled over time may have slightly changed, for example shifting research attention from management of abundant species to detection of rare species requiring conservation attention. The species-level random effect (and data filtering procedure in Appendix S2) controls for species turnover, but would not capture a shift in focus from high-density to low-density populations within the geographic range of low-density species. Yet, the consistent results across different diet categories and using different methods suggests this possible effect cannot be the only driver of changes in the SDR parameters over time. While we cannot provide a conclusive answer on the causes of these changes, they ultimately indicate that macroecologists should be very careful in drawing conclusions without acknowledging that ecosystems have been severely modified in recent time, and may be still in the process of changing. Macroecology may thus be unable to get better estimates of pre-Anthropocene allometric parameters just by collecting more data. Perhaps, pre-Anthropocene parameters should not be considered as a natural baseline either, as there is no evidence ecosystems were in equilibrium before widespread human modification, for example, some species never realised the distributions implied by their Holocene climatic niches (Svenning \& Skov, 2004).

Our understanding of natural world is biased to a compromised situation. The collection of large databases including data collected over long time spans may help us to capture these biases and possibly correct for them. It is crucial that the effect of humans is increasingly considered while assessing and interpreting natural patterns and their causes.

\section{AUTHOR CONTRIBUTIONS}

LS conceived the original idea, collected all data, performed the analyses, and drafted the original version of the manuscript. NJBI made substantial contributions to the framing of the study, definition of the methodology, interpretation of the results, and the writing.

\section{PEER REVIEW}

The peer review history for this article is available at https://publons.com/publon/10.1111/ele.13743.

\section{OPEN RESEARCH BADGES}

\section{dit)}

This article has earned Open Data and Open Materials badges. Data and materials are available at: 10.6084/ m9.figshare. 14199302

\section{DATA AVAILABILITY STATEMENT}

The dataset used for the analyses is archived in Figshare (https://doi.org/10.6084/m9.figshare.14199302).

\section{ORCID}

Luca Santini (D) https://orcid.org/0000-0002-5418-3688

Nick J. B. Isaac (D) https://orcid.org/0000-0002-4869-8052

\section{REFERENCES}

Allen, A.P., Brown, J.H. \& Gillooly, J.F. (2002) Global biodiversity, biochemical kinetics, and the energetic-equivalence rule. Science, 297(5586), 1545-1548.

Araújo, M.B. \& Pearson, R.G. (2005) Equilibrium of species' distributions with climate. Ecography, 28(5), 693-695.

Benítez-López, A., Alkemade, R., Schipper, A.M., Ingram, D.J., Verweij, P.A., Eikelboom, J.A.J. et al. (2017) The impact of hunting on tropical mammal and bird populations. Science, 356(6334), 180-183.

Berger, J. (2007) Fear, human shields and the redistribution of prey and predators in protected areas. Biology Letters, 3, 620-623. 
Bernardo-Madrid, R., Calatayud, J., González-Suárez, M., Rosvall, M., Lucas, P.M., Rueda, M. et al. (2019) Human activity is altering the world's zoogeographical regions. Ecology Letters, 22, $1297-1305$.

Blackburn, T.M., Brown, V.K.V., Doube, B.B.M., Greenwood, J.J.D.J.J.D., Lawton, J.H., Stork, N.E.N. et al. (1993) The relationship between abundance and body size in natural animal assemblages. Journal of Animal Ecology, 62, 519-528.

Brown, J.H., Gillooly, J.F., Allen, A.P., Savage, V.M. \& West, G.B (2004) Toward a metabolic theory of ecology. Ecology, 85, 1771-1789.

Carbone, C. \& Gittleman, J.L. (2002) A common rule for the scaling of carnivore density. Science, 295(5563), 2273-2276.

Carbone, C., Rowcliffe, J.M., Cowlishaw, G. \& Isaac, N.J.B. (2007) The scaling of abundance in consumers and their resources: implications for the energy equivalence rule. American Naturalist, 170, 479-484.

Cardillo, M., Mace, G.M., Jones, K.E., Bielby, J., Bininda-Emonds, O.R.P., Sechrest, W. et al. (2005) Multiple causes of high extinction risk in large mammal species. Science, 309(5738), 1239-1241.

Cooke, R.S.C., Eigenbrod, F. \& Bates, A.E. (2019) Projected losses of global mammal and bird ecological strategies. Nature Communications, 10, 2279.

Cosset, C.C.P., Gilroy, J.J., Srinivasan, U., Hethcoat, M.G. \& Edwards, D.P. (2020) Mass-abundance scaling in avian communities is maintained after tropical selective logging. Ecology and Evolution, 10(6), 2803-2812.

Damuth, J. (1981) Population density and body size in mammals. Nature, 290, 699-700.

Damuth, J. (1987) Interspecific allometry of population density in mammals and other animals: the independence of body mass and population energy-use. Biological Journal of the Linnean Society, 31, 193-246.

Delong, J.P. \& Vasseur, D.A. (2012) Size-density scaling in protists and the links between consumer-resource interaction parameters. Journal of Animal Ecology, 81, 1193-1201.

Di Marco, M. \& Santini, L. (2015) Human pressures predict species' geographic range size better than biological traits. Global Change Biology, 21, 2169-2178.

Diamond, J.M. (1972) Biogeographic kinetics: estimation of relaxation times for Avifaunas of Southwest Pacific Islands. Proceedings of the National Academy of Sciences, 69, 3199-3203.

Dornelas, M., Gotelli, N.J., McGill, B., Shimadzu, H., Moyes, F., Sievers, C. et al. (2014) Assemblage time series reveal biodiversity change but not systematic loss. Science, 344(6181), 296-299.

Ernest, S.K.M., Enquist, B.J., Brown, J.H., Charnov, E.L., Gillooly, J.F., Savage, V.M. et al. (2003) Thermodynamic and metabolic effects on the scaling of production and population energy use. Ecology Letters, 6, 990-995.

Estes, J.A., Terborgh, J., Brashares, J.S., Power, M.E., Berger, J., Bond, W.J. et al. (2011) Trophic downgrading of planet Earth. Science, 333(6040), 301-306.

Faurby, S. \& Araújo, M.B. (2016) Anthropogenic impacts weaken Bergmann's rule. Ecography, 40(6), 683-684.

Floejgaard, C., Pedersen, P.B.M., Sandom, C., Svenning, J.C. \& Ejrnæs, R. (2020). Exploring a natural baseline for large herbivore biomass. bioRxiv. https://doi. org/10.1101/2020.02.27.968461.

Gaynor, K.M., Hojnowski, C.E., Carter, N.H. \& Brashares, J.S. (2018) The influence of human disturbance on wildlife nocturnality. Science, 360(6394), 1232-1235.

Gonzalez-Suarez, M., Gomez, A. \& Revilla, E. (2013) Which intrinsic traits predict vulnerability to extinction depends on the actual threatening processes. Ecosphere, 4, 1-16.

Harfoot, M.B.J., Newbold, T., Tittensor, D.P., Emmott, S., Hutton, J., Lyutsarev, V. et al. (2014) Emergent global patterns of ecosystem structure and function from a mechanistic general ecosystem model. PLoS Biology, 12(4), e1001841.
Hatton, I.A., Dobson, A.P., Storch, D., Galbraith, E.D. \& Loreau, M. (2019) Linking scaling laws across eukaryotes. Proceedings of the National Academy of Sciences, 116, 21616-21622.

Hoeks, S., Huijbregts, M.A.J., Busana, M., Harfoot, M.B.J., Svenning, J.-C. \& Santini, L. (2020) Mechanistic insights into the role of large carnivores for ecosystem structure and functioning. Ecography, 43(12), 1752-1763.

Isaac, N.J.B., Storch, D. \& Carbone, C. (2011) Taxonomic variation in size-density relationships challenges the notion of energy equivalence. Biology Letters, 7, 615-618.

Isaac, N.J.B., Storch, D. \& Carbone, C. (2013) The paradox of energy equivalence. Global Ecology and Biogeography, 22, 1-5.

Kleiber, M. (1932) Body size and metabolism. Hilgardia, 6, 315-353.

Malhi, Y., Doughty, C.E., Galetti, M., Smith, F.A., Svenning, J.C. \& Terborgh, J.W. (2016) Megafauna and ecosystem function from the Pleistocene to the Anthropocene. Proceedings of the National Academy of Sciences, 113, 838-846.

Marquet, P.A., Navarrete, S.A. \& Castilla, J.C. (1995) Body size, population density, and the energetic equivalence rule. Journal of Animal Ecology, 64, 325-332.

McGill, B.J. (2008) Exploring predictions of abundance from body mass using hierarchical comparative approaches. American Naturalist, 172, 88-101.

McGill, B. (2011) A macroecological approach to the equilibrial vs. Nonequilibrial debate using bird populations and communities. In: The Balance of Nature and Human Impact (ed Rodhe, K.). Cambridge Univ. Press, Cambridge, pp. 103-118.

McGill, B.J., Dornelas, M., Gotelli, N.J. \& Magurran, A.E. (2015) Fifteen forms of biodiversity trend in the anthropocene. Trends in Ecology \& Evolution, 30, 104-113.

Munn, A.J., Dunne, C., Müller, D.W.H. \& Clauss, M. (2013) Energy in-equivalence in Australian marsupials: evidence for disruption of the continent's mammal assemblage, or are rules meant to be broken? PLoS One, 8, e57449.

Newbold, T., Hudson, L.N., Arnell, A.P., Contu, S., Palma, A.D., Ferrier, S. et al. (2016) Has land use pushed terrestrial biodiversity beyond the planetary boundary? A global assessment. Science, 353(6296), 288-291.

Nilsen, E.B., Finstad, A.G., Næsje, T.F. \& Sverdrup-Thygeson, A. (2013) Using mass scaling of movement cost and resource encounter rate to predict animal body size-Population density relationships. Theoretical Population Biology, 86, 23-28.

Pedersen, R.Ø., Faurby, S. \& Svenning, J. (2017a) Shallow size-density relations within mammal clades suggest greater intra-guild ecological impact of large-bodied species. Journal of Animal Ecology, 86, 1205-1213.

Pfeifer, M., Lefebvre, V., Peres, C.A., Banks-Leite, C., Wearn, O.R., Marsh, C.J. et al. (2017) Creation of forest edges has a global impact on forest vertebrates. Nature, 551, 187-191.

Prugh, L.R., Stoner, C.J., Epps, C.W., Bean, W.T., Ripple, W.J., Laliberte, A.S. et al. (2009) The rise of the mesopredator. BioScience, 59, 779-791.

Purvis, A., Agapow, P.M., Gittleman, J.L. \& Mace, G.M. (2000) Nonrandom extinction and the loss of evolutionary history. Science, 288(5464), 328-330.

Raffalovich, L.E., Deane, G.D., Armstrong, D. \& Tsao, H.S. (2008) Model selection procedures in social research: Monte-Carlo simulation results. Journal of Applied Statistics, 35, 1093-1114.

Rapacciuolo, G., Marin, J., Costa, G.C., Helmus, M.R., Behm, J.E., Brooks, T.M. et al. (2017) The signature of human pressure history on the biogeography of body mass in tetrapods. Global Ecology and Biogeography, 26, 1022-1034.

Ripple, W.J., Estes, J.A., Beschta, R.L., Wilmers, C.C., Ritchie, E.G., Hebblewhite, M. et al. (2014) Status and ecological effects of the world's largest carnivores. Science, 343(6167), 1241484.

Ripple, W.J., Wolf, C., Newsome, T.M., Hoffmann, M., Wirsing, A.J. \& McCauley, D.J. (2017) Extinction risk is most acute for the world's largest and smallest vertebrates. Proceedings of the National Academy of Sciences, 114(40), 10678-10683. 
Ritchie, E.G. \& Johnson, C.N. (2009) Predator interactions, mesopredator release and biodiversity conservation. Ecology Letters, 12, 982-998.

Russo, S.E., Robinson, S.K. \& Terborgh, J. (2003) Size-abundance relationships in an Amazonian bird community: Implications for the energetic equivalence rule. American Naturalist, 161, 267-283.

Santini, L., González-Suárez, M., Rondinini, C. \& Di Marco, M. (2017) Shifting baseline in macroecology? Unraveling the influence of human impact on mammalian body mass. Diversity and Distributions, 23, 640-649.

Santini, L., Isaac, N.J.B. \& Ficetola, G.F. (2018) TetraDENSITY: a database of population density estimates in terrestrial vertebrates. Global Ecology and Biogeography, 27, 787-791.

Silva, M., Brown, J.H. \& Downing, J.A. (1997) Differences in population density and energy use between birds and mammals: a macroecological perspective. Journal of Animal Ecology, 66, 327-340.

Smith, F.A., Lyons, K., Morgan Ernest, S.K., Jones, K.E., Kaufman, D.M., Dayan, T. et al. (2003) Body mass of late quaternary mammals. Ecology, 84, 3403.

Svenning, J.C. \& Skov, F. (2004) Limited filling of the potential range in European tree species. Ecology Letters, 7, 565-573.

Terborgh, J.W. (2015) Toward a trophic theory of species diversity. Proceedings of the National Academy of Sciences, 112, 11415-11422.

Tilman, D., May, R.M., Lehman, C.L. \& Nowak, M.A. (1994) Habitat destruction and the extinction debt. Nature, 371, 65-66.

Torres-Romero, E.J. \& Olalla-Tárraga, M.Á. (2015) Untangling human and environmental effects on geographical gradients of mammal species richness: a global and regional evaluation. Journal of Animal Ecology, 84, 851-860.

Tucker, M.A., Böhning-Gaese, K., Fagan, W.F., Fryxell, J.M., Van Moorter, B., Alberts, S.C. et al. (2018) Moving in the Anthropocene: Global reductions in terrestrial mammalian movements. Science, 359(6374), 466-469.
Tucker, M., Santini, L., Carbone, C. \& Mueller, T. (2020) Mammal population densities at a global scale are higher in humanmodified areas. Ecography, 44(1), 1-13.

Upham, N.S., Esselstyn, J.A. \& Jetz, W. (2019) Inferring the mammal tree: Species-level sets of phylogenies for questions in ecology, evolution, and conservation. PLoS Biology, 17, e3000494.

Venter, O., Sanderson, E.W., Magrach, A., Allan, J.R., Beher, J., Jones, K.R. et al. (2016) Sixteen years of change in the global terrestrial human footprint and implications for biodiversity conservation. Nature Communications, 7, 11.

White, E.P., Ernest, S.K.M., Kerkhoff, A.J. \& Enquist, B.J. (2007) Relationships between body size and abundance in ecology. Trends in Ecology \& Evolution, 22(6), 323-330.

Wilman, H., Belmaker, J., Simpson, J., de la Rosa, C., Rivadeneira, M.M. \& Jetz, W. (2014) EltonTraits 1.0: Species-level foraging attributes of the world's birds and mammals. Ecology, 95, 2027.

Yirga, G., Ersino, W., De Iongh, H.H., Leirs, H., Gebrehiwot, K., Deckers, J. et al. (2013) Spotted hyena (Crocuta crocuta) coexisting at high density with people in Wukro district, northern Ethiopia. Mammalian Biology, 78, 193-197.

\section{SUPPORTING INFORMATION}

Additional supporting information may be found online in the Supporting Information section.

How to cite this article: Santini L, Isaac NJ. Rapid Anthropocene realignment of allometric scaling rules. Ecology Letters. 2021;00:1-10. https://doi. org/10.1111/ele.13743 